Research Article

\title{
The prognostic value of the serum ferritin in a southern Brazilian cohort of patients with Gaucher disease
}

Tiago Koppe ${ }^{1,2}$; Divair Doneda ${ }^{3}$; Marina Siebert ${ }^{1,6,7}$; Livia Paskulin ${ }^{1,2}$; Matheus Camargo ${ }^{1}$; Kristiane Michelin Tirelli ${ }^{4}$; Filippo Vairo ${ }^{4}$; Liane Daudt ${ }^{1,5}$ and Ida Vanessa D. Schwartz ${ }^{1,2,4,6}$

${ }^{1}$ Departamento de Genética, Universidade Federal do Rio Grande do Sul (UFRGS), Porto Alegre, RS, Brazil.

${ }^{2}$ Programa de Pós-Graduação em Genética e Biologia Molecular, Universidade Federal do Rio Grande do Sul (UFRGS), Porto Alegre, RS, Brazil.

${ }^{3}$ Laboratório de Técnica Dietética, Faculdade de Medicina, Universidade Federal do Rio Grande do Sul (UFRGS), Porto Alegre, RS, Brazil.

${ }^{4}$ Serviço de Genética Médica, Hospital de Clínicas de Porto Alegre (HCPA), Porto Alegre, RS, Brazil.

${ }^{5}$ Serviço de Hematologia Clínica, Hospital de Clínicas de Porto Alegre (HCPA), Porto Alegre, RS, Brazil.

${ }^{6}$ Basic Research and Advanced Investigations in Neurosciences (BRAIN) Laboratory, Hospital de Clínicas (HCPA), Porto Alegre, RS, Brazil.

${ }^{7}$ Unidade de Análises Moleculares e de Proteinas (UAMP), Centro de Pesquisa Experimental, Hospital de Clínicas de Porto Alegre (HCPA), Porto Alegre, RS, Brazil.

\begin{abstract}
The clinical utility of serum ferritin as a biomarker of disease severity and prognosis in Gaucher disease (GD) is still debated. Here, we aimed to evaluate ferritin and its relation to clinicolaboratory parameters of GD patients seen at the Reference Center for Gaucher Disease of Rio Grande do Sul, Brazil, so as to gather evidence on the utility of ferritin as a biomarker of this condition. A retrospective chart review was performed collecting pre- and posttreatment data from GD patients. Eighteen patients with ferritin levels available before and after treatment were included in the study. Nine of these participants were males, and seventeen had type I GD. All patients were given either enzyme replacement $(n=16)$ or substrate reduction therapy $(n=2)$, and ferritin was found to decrease from 756 [318-1441] $\mathrm{ng} / \mathrm{mL}$ at baseline to 521 [227-626] ng/mL $(p=0.025)$ after 28.8 months of treatment. Serum ferritin levels did not correlate with measures of disease severity, but showed an association with age at onset of treatment $(\rho=$ $0.880 ; n=18 ; p<0.001)$. In conclusion, although serum ferritin did not correlate with disease severity, after a median 28.8 months of treatment, clinical outcomes had clearly improved, and ferritin levels had decreased.
\end{abstract}

Keywords: ferritin, biomarkers, Gaucher disease, iron metabolism.

Received: May 17, 2015; Accepted: September 28, 2015.

\section{Introduction}

Gaucher disease (GD) (OMIM \#230800) is a metabolic disorder caused by a deficiency in lysosomal glucocerebrosidase activity (EC 3.2.1.45) due to mutations in the GBA1 gene (Grabowski et al., 2014). The worldwide prevalence of GD is about 1:40,000-200,000 (Poorthuis et al., 1999; Pinto et al., 2004), and its clinical manifestations include multisystem organomegaly, pancytopenia and bone complications (Pastores and Hughes, 2000; Grabowski et

Send correspondence to Ida V. Doederlein Schwartz. Programa de Pós-Graduação em Genética e Biologia Molecular, Universidade Federal do Rio Grande do Sul (UFRGS), Hospital de Clínicas de Porto Alegre. Rua Ramiro Barcelos 2350, Bairro Rio Branco, 90035-903 Porto Alegre, RS, E-mail: ischwartz@ hcpa.ufrgs.br. al., 2014). Although the mechanisms by which GBAl gene mutations influence GD phenotype remain largely unknown, the main pathogenesis of this disorder is believed to be the lysosomal accumulation of glucocerebroside in mononuclear phagocytes. This process triggers the expression of cytokines and other inflammatory molecules which, in turn, engage other immune cells and ultimately lead to a systemic immune response (Barak et al., 1999; Cox, 2001; Boven et al., 2004; Liu et al., 2012; Pandey and Grabowski, 2013; Vairo et al., 2013; Thomas et al., 2014). Several circulating molecules thought to be secreted by these lipidladen macrophages have been studied as biological markers of disease burden and/or response to enzyme replacement therapy (ERT) (Aerts et al., 2005; Cox, 2006). In this re- 
gard, although lyso-Gb1 has recently emerged as a promising specific biomarker of GD (Fuller et al., 2015), the most frequent and consistently altered molecules in GD have been found to be the following: chitotriosidase (EC 3.2.1.14), angiotensin converting enzyme (EC 3.4.15.1), CCL18 (P55774), tartarate-resistant acid phosphatase (EC3.1.3.2) and serum ferritin (SF) (P02792 and P02794) (Aronson, 2005; Boot et al., 2009; Hughes and Pastores, 2013; Thomas et al., 2013, 2014). Over the past few years, several studies have described hyperferritinemia in GD patients and demonstrated its reduction after the initiation of treatment. The first study to report hyperferritinemia over the course of GD was published by Morgan et al. (1983), and since then these findings have been replicated in different cohorts worldwide (Poll et al., 2002; Grosbois et al., 2009; Saadi et al., 2010; Stein et al., 2010; Stirnemann et al., 2010; Stirnemann et al., 2011; Mekinian et al., 2012). The reduction in SF exhibited by patients with GD undergoing ERT could be indicative of a positive clinical outcome (Stirnemann et al., 2010; Vigan et al., 2014), although no studies to date have identified a clear association between SF levels and GD severity. In Brazilian patients, these findings have yet to be replicated. As such, the aim of this study was to evaluate the clinical use of SF as a biomarker of GD severity and/or response to treatment in a Brazilian cohort of GD patients.

\section{Material and Methods}

A retrospective chart review of patients with GD treated at the GD Reference Center of Rio Grande do Sul, Brazil, was performed. An extensive database of patients with GD was analyzed, and all those who had at least two measurements of SF levels - one before and the other after the onset of GD therapy (i.e., ERT or substrate reduction therapy - SRT) - were included in the study.

Pre-treatment SF levels were defined as the most recent measurements available in the database prior to the onset of treatment, and post-treatment SF was evaluated based on the most recent measurement available for each patient in the dataset. Hyperferritinemia was defined as SF $>322$ $\mathrm{ng} / \mathrm{mL}$ in males and $>291 \mathrm{ng} / \mathrm{mL}$ in females. All other variables were matched to SF levels by date to determine their status as pre- or post-treatment measures. In the referral center, the diagnosis of GD is confirmed in all cases by reduced glucocerebrosidase activity (i.e., $<10 \%$ of normal) in leukocytes. All patients received standard care, and had their clinical history, physical examinations, lab tests and medical imaging results recorded during routine medical assessments.

Asthenia, abdominal pain, bone involvement, bleeding, splenomegaly and hepatomegaly were evaluated based on clinical assessments or ancillary tests recommended by current guidelines. SSI (Severity Score Index) was calculated on every medical visit as described in Zimran et al. (1989). Quantitative variables were expressed as median [25th-75th percentiles], and categorical variables were displayed as absolute frequencies. Non-parametric tests were used to compare pre- and post-treatment variables and assess treatment effects. Two-tailed Wilcoxon signed-rank tests were used to analyze quantitative variables, while McNemar tests were involved in the evaluation of categorical data. Additionally,Spearman correlation analyses were carried out to assess the relationship between quantitative variables and SF.All tests were performed using SPSS 18 $\left(\mathrm{IBM}^{\mathbb{R}}\right)$ and statistical significance was considered when $p$ $<0.05$.

This study was approved by the Research Ethics Committee of the Hospital de Clínicas de Porto Alegre, Brazil.

\section{Results}

Eighteen patients with a diagnosis of GD met inclusion criteria for this study $($ male $=9$, females $=9$; GD type I = 17; GD type III = 1). Eleven patients had a N370S/L444P genotype, three were N370S/N370S, two were N370S/RecNciI, one was E349K/S366N and one, L444P/L444P. Median age at diagnosis and treatment onset was 39.5 years [15.7-51.2] and 41.1 years [24.6-52.9], respectively. Three patients had undergone splenectomy, one had cirrhosis and none had hepatocellular carcinoma. Patients had no history of blood transfusions, although three female patients received a short course of iron supplementation over the follow-up and were excluded from the analysis of serum iron levels and transferrin saturation. At inclusion, sixteen patients were on ERT (velaglucerase alpha $=1$; taliglucerase alpha $=2$; imiglucerase $=$ 13), and received a mean dosage of $21.56 \pm 12.21 \mathrm{UI} / \mathrm{kg} / \mathrm{inf}$ every 2 weeks. Additionally, two patients were receiving SRT (eliglustat $=1$; miglustat $=1$ ). None of the 18 participants had any other biochemical evidence of iron overload, such as high transferrin saturation.

A consistent effect of therapy was observed in comparison between pre- and post-treatment clinical and laboratory data (Table 1). Treatment was also associated with a significant reduction in SF levels (Table 1). Prior to treatment, 14 patients $(77.8 \% ; 9 / 9$ males and 5/9 females) exhibited hyperferritinemia, including all three splenectomized patients. All females without hyperferritinemia were younger than 29 years. In the post-treatment period, 12 patients $(66.7 \%$; 7/9 males and 5/9 females) presented hyperferritinemia, including all three splenectomized patients. The subgroup of the hyperferritinemic patients that normalized SF and the subgroup that did not normalize did not differ regarding all the other analyzed variables (data not shown). Correlations between SF and hemoglobin, platelets, alanine aminotransferase, lactate dehydrogenase, chitotriosidase, and SSI were not statistically significant (data not shown). However, pre-treatment SF levels were associated with age at onset of the treatment $(\rho=0.880 ; n=$ 
Table 1 - Hyperferritinemia in patients with Gaucher disease: pre- and post-treatment data.

\begin{tabular}{|c|c|c|c|}
\hline & Pre-treatment $(n=18)$ & Post-treatment $(n=18)$ & $p$ \\
\hline \multicolumn{4}{|l|}{ Clinical findings: } \\
\hline - Abdominal pain & 11 & 5 & 0.070 \\
\hline - Bleeding* & 10 & 2 & 0.008 \\
\hline - Bone involvement ${ }^{1}$ & 14 & 12 & 0.500 \\
\hline - Splenomegaly ${ }^{2}$ & $14 / \mathrm{n}=15$ & $11 / \mathrm{n}=15$ & 0.250 \\
\hline - Hepatomegaly & 11 & 6 & 0.125 \\
\hline$-\mathrm{BMI}^{3}\left(\mathrm{~kg} / \mathrm{m}^{2}\right)$ & $23.8[20.9-27.7]$ & $24.6[21.6-28.1]$ & 0.170 \\
\hline Hemoglobin* (g/dL) & $12.6[10.1-13.9]$ & 14 [11.6-15] & 0.005 \\
\hline Leukocytes $(x 103 / \mu \mathrm{L})^{*}$ & $4.15[2.93-6.8]$ & $4.9[4.5-7]$ & 0.050 \\
\hline Platelets* $(x 103 / \mu \mathrm{L})$ & $79[63.7-146.7]$ & $145.5[116-171]$ & 0.002 \\
\hline ALT (IU/L) & $22.5[15-35.7]$ & $27[18-43] / \mathrm{n}=17$ & 0.093 \\
\hline LDH (IU/L) & $317[246-360] / \mathrm{n}=15$ & $296[238-368] / \mathrm{n}=17$ & 0.778 \\
\hline $\begin{array}{l}\text { Chitotriosidase* }(\mathrm{x} 103) \\
\mathrm{nmol} / \mathrm{h} / \mathrm{mL})\end{array}$ & $14[7.9-14.7]$ & $3.7[1.7-5.5]$ & 0.002 \\
\hline $\mathbf{S S I}^{4} *$ & $7[4-12] / n=15$ & $2[1-5.5] / n=17$ & 0.001 \\
\hline BMB score ${ }^{5}$ & $8.5[4.5-12] / \mathrm{n}=14$ & $7[4.25-10] / \mathrm{n}=12$ & 0.180 \\
\hline \multicolumn{4}{|l|}{ Serum ferritin $(\mathrm{ng} / \mathrm{mL})^{*}$} \\
\hline - Total* & $756[318-1441]$ & $521[227-626]$ & 0.025 \\
\hline - Male* & $811[614-1544] / n=9$ & $528[369-653] / n=9$ & 0.038 \\
\hline - Female & $328[190-1174] / \mathrm{n}=9$ & $362[123-624] / n=9$ & 0.374 \\
\hline Transferrin saturation (\%) & $19[14-32] / n=8$ & $28[23-34] / \mathrm{n}=13$ & 0.138 \\
\hline Serum iron $(\mu \mathrm{g} / \mathrm{dL})$ & $56[46-89] / \mathrm{n}=10$ & $91[72-99] / \mathrm{n}=13$ & 0.176 \\
\hline
\end{tabular}

Values expressed as median [25th-75th percentiles] or absolute count, unless otherwise specified; * $p<0.05$ after McNemar or Wilcoxon signed-rank test; Reference values: serum ferritin (males: $22-322 \mathrm{ng} / \mathrm{mL}$ and females: $10-291 \mathrm{ng} / \mathrm{mL})$; transferrin saturation $(25-50 \%)$ and serum iron $(50-170 \mu \mathrm{g} / \mathrm{dL}$ ). ${ }^{1}$ Bone involvement was considered whenever patients mentioned pain/pathological fractures without any other attributable cause, or in the presence of imaging evidence of bone disease (e.g., osteopenia on bone densitometry). ${ }^{2}$ Three patients had undergone splenectomy. ${ }^{3} \mathrm{Body} \mathrm{Mass} \mathrm{Index}\left(\mathrm{Kg} / \mathrm{m}^{2}\right):<$ 18.5 - underweight; $18.5-24.9$ - normal weight; $25-29.9$ - overweight and $>30$ - obesity ${ }^{4}$ Clinical Severity Score Index: $0-9$ - mild; $10-19$ - moderate and $>20$ - severe. ${ }^{5}$ Bone Marrow Burden score: 0-4 - mild; 5-8 - moderate and 9-16 - severe.

18; $p<0.001)$ and Body Mass Index (BMI) $(\rho=0.713 ; n=$ $14 ; p<0.005)$.

\section{Discussion}

This study aimed to investigate the clinical use of SF as a biomarker of disease severity and/or response to treatment in GD. Our results showed that hyperferritinemia is a common occurrence in GD, especially in untreated, older male patients with a higher BMI. Our results are also in agreement with findings obtained both from general and GD populations. SF levels are known to be influenced by sex and age, so that reference values differ by age and gender, in addition to population characteristics, such as ethnicity and presence of other medical comorbidities (Luxton et al., 1977; Vicente et al., 1990; Custer et al., 1995; Koziol et al., 2001; Pan and Jackson, 2008; Ferraro et al., 2012). Growing evidence has shown that SF is associated with BMI, obesity and insulin resistance, and nonalcoholic fatty liver disease (Guglielmi et al., 2015). In addition, several studies have found that women, regardless of age and pres- ence of medical comorbidities, always tend to have lower $\mathrm{SF}$ values than men. Additionally, premenopausal women have dramatically lower SF levels than postmenopausal females. The peaking of SF levels in menopause has not been associated with transferrin saturation (Koziol et al., 2001), but has been found to be related to hepcidin, the central peptide in iron metabolism regulation, whose levels are very strongly correlated with those of SF (Galesloot et al., 2011). The cutoff for hyperferritinemia varies across contexts. In our sample, only $55 \%$ of the women were labeled as hyperferritinemic according to the cutoff points provided by the laboratory where the analyses were performed. However, when the female cutoff values suggested by the American Association for the Study of Liver Diseases (15$150 \mathrm{ng} / \mathrm{mL}$ ) (Bacon et al., 2011) were applied to the sample, the percentage of females categorized as hyperferritinemic was found to be higher (data not shown).

The magnitude of the increase in SF levels in patients with GD was very similar to that observed in a previous study (median $756 v s .739 \mathrm{ng} / \mathrm{mL}$, respectively) (Mekinian et al., 2012), but lower than that reported by Stein et al. 
(2010), who found a 3.7-fold elevation above the upper limit of normality. These differences and similarities may be attributable to mean sample age, which was very similar between the present study and that performed by Mekinian et al. (2012), but much lower in our sample than in the participants recruited by Stein et al. (2010).

Our data did not support the use of SF as a biomarker of GD severity. Previous studies have shown the same findings, suggesting that SF levels may not be influenced by disease severity per se, but by the number of years of disease activity (i.e., older individuals). Low SF is pathognomonic of iron deficiency and can be used to detect this condition with almost $100 \%$ specificity. However, high SF levels are not necessarily indicative of iron overload. Therefore, a transferrin saturation cutoff value $>45 \%$ has been suggested as a good predictor of iron overload (Gilles, 2013). In inflammatory conditions, such as GD, iron becomes unavailable for erythropoiesis, despite adequate iron storage levels. This phenomenon is called functional iron deficiency and is characteristic of the anemia of chronic disorders. So, hyperferritinemia may exist in the presence or in the absence of iron overload, and recent studies have demonstrated macrophage iron accumulation in anemia of chronic disease (King and Weiss, 2014). In this regard, iron overload in inflammatory cells has also been identified in conditions such as Parkinson's disease, multiple sclerosis and other neurodegenerative disorders using noninvasive imaging methods to quantify iron levels in different tissues (Stoll and Bendszus, 2009; Böttcher et al., 2013; Mehta et al., 2013). The analysis of participant iron profiles showed that transferrin saturation and serum iron levels also appeared to increase after treatment, although this change was not statistically significant in our sample. Since iron deficiency and iron deficiency anemia is far more frequent in the Brazilian population than in people from developed countries and this tendency is reflected in Brazilian GD cohorts (Sobreira et al., 2007), this lack of statistical significance could reflect a poor-iron diet. Nonetheless, taken together these findings may suggest that patients under treatment may have higher concentrations of iron available for erythropoiesis.

In conclusion, SF does not appear to be a useful biomarker of disease severity in GD, but can be used as a biomarker of diagnosis and response to treatment. Treatment also seemed to increase serum iron and transferrin saturation levels, increasing the amount of iron available for erythropoiesis. These findings need to be further evaluated in order to clarify the relation between SF and iron metabolism in GD patients.

\section{Acknowledgments}

Financial support for this study was provided by Conselho Nacional de Desenvolvimento Científico e Tecnológico (CNPq, Brazil), Fundo de Incentivo à Pesquisa e Eventos do Hospital de Clínicas de Porto Alegre
(FIPE/HCPA), and Fundação de Amparo a Pesquisa do Estado do Rio Grande do Sul (FAPERGS, RS, Brazil).

\section{References}

Aerts JM, Hollak CE, van Breemen M, Maas M, Groener JE and Boot RG (2005) Identification and use of biomarkers in Gaucher disease and other lysosomal storage diseases.Acta Paediatr Suppl 2005 94:43-46.

Aronson JK (2005) Biomarkers and surrogate endpoints. Br J Clin Pharmacol 59:491-494.

Bacon BR, Adams PC, Kowdlay KV, Powell LW, Tavill AS and American Association for the Study of Liver Diseases (2011) Diagnosis and management of hemochromatosis: Practice guideline from the American Association for the Study of Liver Diseases. Hepatology 54:328-343.

Barak V, Acker M, Nisman B, Kalickman I, Abrahamov A, Zimran A, Yatziv S (1999) Cytokines in Gaucher's disease. Eur Cytokine Netw 10:205-210.

Boot RG, van Breemen MJ, Wegdam W, Sprenger RR, de Jong S, Speijer D, Hollak CE, van Dussen L, Hoefsloot HC, Smilde AK, et al. (2009) Gaucher disease: a model disorder for biomarker discovery. Expert Rev Proteomics 6:411-419.

Böttcher T, Rolfs A, Meyer B, Grossmann A, Berg D, Kropp P, Benecke R and Walter U (2013) Clinical, genetic, and brain sonographic features related to Parkinson's disease in Gaucher disease. J Neurol 260:2523-2531.

Boven LA, van Meurs M, Boot RG, Mehta A, Boon L, Aerts JM, Laman JD (2004) Gaucher cells demonstrate a distinct macrophage phenotype and resemble alternatively activated macrophages. Am J Clin Pathol 122:359-369.

Cox TM (2001) Gaucher disease: understanding the molecular pathogenesis of sphingolipidoses. J Inherit Metab Dis 24 (Suppl 2):106-121.

Custer EM, Finch CA, Sobel RE and Zettner A (1995) Population norms for serum ferritin. J Lab Clin Med 126:88-94.

Ferraro S, Mozzi R, Panteghini M. (2012) Revaluating serum ferritin as a marker of body iron stores in the traceability era. Clin Chem Lab Med 50:1911-1916.

Fuller M, Szer J, Stark S and Fletcher JM (2015) Rapid, single-phase extraction of glucosylsphingosine from plasma: a universal screening and monitoring tool. Clin Chim Acta. 29:6-10.

Galesloot TE, Vermeulen SH, Geurts-Moespot AJ, Klaver SM, Kroot JJ, van Tienoven D, Wetzels JF, Kiemeney LA, Sweep FC, den Heijer M and Swinkels DW (2011) Serum hepcidin: reference ranges and biochemical correlates in the general population. Blood. 117:e218-225.

Gilles A (2013) Iron's ups and downs. Rev Med Brux 34:328-334.

Grosbois B, Revest M, Decaux O (2009) Major hyperferritinemia, autoimmune thrombocytopenic purpura and lymphocytic lymphoma in Gaucher disease. Presse Med 38:2S56-2S57.

Guglielmi V, D'Adamo M, Bellia A, Ciotto RT, Federici M, Lauro D and Sbraccia P (2015) Iron status in obesity: an independent association with metabolic parameters and effect of weight loss. Nutr Metab Cardiovasc Dis 25:541-547.

Hughes DA and Pastores GM (2013) Haematological manifestations and complications of Gaucher disease. Curr Opin Hemato20:41-47.

King RL, and Weiss MJ (2014) Iron-laden macrophage in autoimmune disease. Blood. 123:469. 
Koziol JA, Ho NJ, Felitti VJ and Beutler E (2001) Reference centiles for serum ferritin and percentage of transferrin saturation, with application to mutations of the HFE gene. Clin Chem 47:1804-1810.

Liu J, Halene S, Yang M, Iqbal J, Yang R, Mehal WZ, Chuang WL, Jain D, Yuen T, Sun L, et al. (2012) Gaucher disease gene GBA functions in immune regulation. Proc Natl Acad Sci USA 109:10018-10023.

Luxton AW, Walker WH, Gauldie J, Ali AM and Pelletier C (1977) A radioimmunoassay for serum ferritin. Clin Chem. 23:683-689.

Mehta V, Pei W, Yang G, Li S, Swamy E, Boster A, Schmalbrock $P$ and Pitt D (2013) Iron is a sensitive biomarker for inflammation in multiple sclerosis lesions. PLoS One 8:e57573.

Mekinian A, Stirnemann J, Belmatoug N, Heraoui D, Fantin B, Fain O, Charpentier A and Rose C (2012) Ferritinemia during type 1 Gaucher disease: mechanisms and progression under treatment. Blood Cells Mol Dis 49:53-57.

Morgan MA, Hoffbrand AV, Laulicht M, Luck W and Knowles S (1983) Serum ferritin concentration in Gaucher's disease. Br Med J 286:1864.

Pan Y and Jackson RT (2008) Insights into the ethnic differences in serum ferritin between black and white US adult men. Am J Hum Biol 20:406-416

Pandey MK and Grabowski GA (2013) Immunological cells and functions in Gaucher disease. Crit Rev Oncog 18:197-220.

Pinto R, Caseiro C, Lemos M, Lopes L, Fontes A, Ribeiro H, Pinto E, Silva E, Rocha S, et al. (2004) Prevalence of lysosomal storage diseases in Portugal. Eur J Hum Genet 12:87-92.

Poll LW, Koch JA, Willers R, Aerts H, Scherer A, Häussinger D, Mödder U and vom Dahl S (2002) Correlation of bone marrow response with hematological, biochemical, and visceral responses to enzyme replacement therapy of nonneuronopathic (type 1) Gaucher disease in 30 adult patients. Blood Cells Mol Dis. 28:209-220.

Poorthuis BJ, Wevers RA, Kleijer WJ, Groener JE, de Jong JG, van Weely S, Niezen-Koning KE, van Diggelen OP (1999) The frequency of lysosomal storage diseases in The Netherlands. Hum Genet 105:151-156.

Saadi T, Rosenbaum H, Veitsman E, Baruch Y (2010) Gaucher's disease type I: a disease masked by the presence of abnormal laboratory tests common to primary liver disease. Eur $\mathrm{J}$ Gastroenterol Hepatol 22:1019-1021.

Sobreira E, Pires RF, Cizmarik M, Grabowski GA (2007). Phenotypic and genotypic heterogeneity in Gaucher disease type 1: a comparison between Brazil and the rest of the world. Mol Genet Metab 90:81-86.

Stein P, Yu H, Jain D and Mistry PK (2010) Hyperferritinemia and iron overload in type 1 Gaucher disease. Am J Hematol 85:472-476.

Stirnemann J, Belmatoug N, Vincent C, Fain O, Fantin B and Mentré F (2010) Bone events and evolution of biologic markers in Gaucher disease before and during treatment. Arthritis Res Ther. 12:R156.

Stirnemann J, Boutten A, Vincent C, Mekinian A, Heraoui D, Fantin B, Fain O, Mentré F, Belmatoug N (2011) Impact of imiglucerase on the serum glycosylated-ferritin level in Gaucher disease. Blood Cells Mol Dis 46:34-38.

Stoll G and Bendszus M (2009) Imaging of inflammation in the peripheral and central nervous system by magnetic resonance imaging. Neuroscience 158:1151-1160.

Thomas AS, Mehta AB and Hughes DA (2013) Diagnosing Gaucher disease: an on-going need for increased awareness amongst haematologists. Blood Cells Mol Dis 50:212-217.

Thomas AS, Mehta AB and Hughes DA (2014) Gaucher disease: haematological presentations and complications. Br J Haematol 165:427-440.

Vairo F, Portela P, Salim PH, Jobim M, Netto C, Dorneles A, Mittlestadt S, Jobim LF and Schwartz IV (2013) KIR genes and HLA class I ligands in Gaucher disease. Gene. 516:5357.

Vicente C, Porto G and de Sousa M (1990) Method for establishing serum ferritin reference values depending on sex and age. J Lab Clin Med 116:779-784.

Vigan M, Stirnemann J, Caillaud C, Froissart R, Boutten A, Fantin B, Belmatoug and, Mentré F (2014) Modeling changes in biomarkers in Gaucher disease patients receiving enzyme replacement therapy using a pathophysiological model. Orphanet J Rare Dis. 9:95.

Zimran A, Sorge J, Gross E, Kubitz M, West C and Beutler E (1989) Prediction of severity of Gaucher's disease by identification of mutations at DNA level. Lancet 2:349-352.

\section{Internet Resources}

Grabowski GA, Petsko GA, Kolodny EH (2014). Gaucher Disease. In: Valle D, Beaudet AL, Vogelstein B, Kinzler KW, Antonarakis SE, Ballabio A, Gibson K and Mitchell G (eds), OMMBID - The Online Metabolic and Molecular Bases of Inherited Diseases, http://ommbid.mhmedical.com/content.aspx?bookid $=474 \&$ Sectionid $=45374148$ (accessed August 20, 2014)

Cox TM (2006) Biomarkers in lysosomal storage diseases. In: Mehta A, Beck M and Sunder-Plassmann G (eds) Fabry Disease: Perspectives from 5 Years of FOS. Oxford PharmaGenesis, Oxford, http://www.ncbi.nlm.nih.gov/books/NBK11586/ (accessed August 20, 2014)

Pastores GM, and Hughes DA (2000) Gaucher Disease. In: Pagon RA, Adam MP, Ardinger HH, et al. (eds), GeneReviews ${ }^{\circledR}$, http://www.ncbi.nlm.nih.gov/books/NBK1269/ (accessed August 10, 2014).,

Associate Editor: Jeremy A. Squire

License information: This is an open-access article distributed under the terms of the Creative Commons Attribution License (type CC-BY), which permits unrestricted use, distribution and reproduction in any medium, provided the original article is properly cited. 